\title{
Increasing Eco-Efficiency Awareness for Ship Loading Process Using Virtual Reality and Gamification
}

\author{
Charles BULLY ${ }^{\mathrm{a}}$, Jordan GERY ${ }^{\mathrm{a}}$, Daniel NÅFORS ${ }^{\mathrm{b}}$, Liang GONG ${ }^{1, \mathrm{~b}}$, Mélanie \\ DESPEISSE $^{\mathrm{b}}$, Björn JOHANSSON $^{\mathrm{b}}$ and Mads Bentzen BILLES $\emptyset^{\mathrm{c}}$ \\ ${ }^{\text {a }}$ ESIEE-Amiens, France \\ ${ }^{\mathrm{b}}$ Chalmers University of Technology, Sweden \\ ${ }^{c} D F D S$, Demark
}

\begin{abstract}
The world is striving for a sustainable future as United Nations proposed the 17 Sustainable Development Goals to reduce the environmental impact and increase societal wellbeing by 2030. In this endeavor, eco-efficiency is considered as one of the key concept to facilitate the successful transition to the sustainable development with the focus to reduce the ecological impact of industry through efficiency improvements. The shipping industry is largely involved in this challenge with a target set by International Maritime Organization to cut emissions from individual ships by $40 \%$ from 2008 levels by 2030 . The ship loading process is believed to have great impact to the overall eco-efficiency as it is not only a time consuming process but also determines the fuel consumption of the transportation. In this study, we aim to incorporate virtual reality (VR) technology and gamification theories to raise the eco-efficiency awareness in the shipping loading process. A VR application for ship loading process was developed using a real world case in the Baltic sea region. Eco-efficiency concept is introduced in different levels based on the gamification theories. Maritime professionals tested the VR application and provided their feedback. The results are positive that combining VR and gamification can be useful to train operators with eco-efficiency in the ship loading operations. It also shows a huge potential to support the shipping industry in this transition towards a more sustainable future.
\end{abstract}

Keywords. Sustainability, eco-efficiency, virtual reality, gamification

\section{Introduction}

Nowadays, thanks to the 17 Sustainable Developments Goals (SDG) [1] proposed by the United Nations (UN), the world is looking for solutions that could reduce the environmental impact and increase societal wellbeing by 2030. Industries are largely involved in this challenge, as they must find solutions to produce in a sustainable way. Digitalization is a solution that could be chosen to solve some of these troubles and bring efficiency and increasing productivity while reduce the environmental impact and the cost of production. It could help factories on simplifying production processes and avoiding wasteful use of natural resources. Virtual Reality (VR), gamification and eco- 
efficiency could improve sustainability and reduce the environmental impact in order to help industries to reach some of the Agenda 2030 objectives [1].

VR is a technology that is growing fast and become more popular in the industry and has many applications in manufacturing [2]. VR can be used for example to answer assembly problematics, virtual prototyping for reengineering solutions [3], continual improvement process [4], factory layout planning [5] or even for the training and education. This last domain is the one aimed for this project.

Gamification is also in a big evolution thanks to the improvement of new technologies like VR or latest computers for example. Gamification is the idea of using "video game elements to improve user experience and user engagement in non-game services and applications" [6]. It aims to increase the acceptance and the use of the application using the natural human instinct of "playing". Gamification can motivate people to learn [7]; it is a new way of management increasingly used in industry and can be applied to a wide range of topics.

Eco-efficiency is a concept that aims to reduce the ecological impact of industry through efficiency improvements [8]. As environmental concerns are a high priority in the global agenda, eco-efficiency is a key concept to transition to a more sustainable society. Eco-efficiency can be achieved by reducing the consumption of natural resources, such as fuel or water, resulting in reduced cost in production and use of products. As consumers are more aware about the environment, companies' interest is increasing in using eco-efficiency to operate in a more sustainable way.

Combining VR with gamification and eco-efficiency could contribute towards the UN Sustainable development Goals (SDGs) of quality education (SDG4), and industry, innovation \& infrastructure (SDG9). To demonstrate the benefits of digital technologies, this paper presents a VR application which was designed as an educative game about eco-efficiency for the shipping industry. The game simulates the loading operation in an eco-efficient mode; it is a way to train people while making them aware of the environmental impact of this operation in order to reduce it. Therefore, this study set out to find out whether gamification theoreis coupled with VR could help to improve the eco-efficiency awareness in the shipping loading process, as well as understanding the potential implication to achieve the SDGs for the industry.

The paper is organized as follows: Section 1 presents some related studies that used VR and gamification in different areas and shows how gamification can be set up in industry. Section 2 describes the experiment where we used VR, gamification and ecoefficiency for the need of shipping industry to train people in the loading operation of ships. Section 3 shows the outcomes of the application followed by a discussion. Finally, the conclusions in Section 4.

\section{Related work}

This section presents how VR and gamification have already been used for a lot of different subjects and problematics and what are the benefits of these technologies. It shows how gamification or VR combined with gamification can be full of benefits, it also shows how to detect eco-efficiency improvements areas that might be primordial for the method later. 


\subsection{Gamification in industry}

Gamification is increasingly used in industry. Using games techniques for serious applications aims to motivate users and consequently to increase their performance and work satisfaction [9]. Robson [10] presents how to implement gamification following five steps:

1. Adapt gamification mechanics to the future players;

2. Have rewards to encourage players and increase satisfaction;

3. Add levels as needed to have a complete experience of the content which the user needs to assimilate;

4. Involve managers as "referees" while employees train themselves;

5. Create a scoring system with visible progress and feedback.

Gamification can overcome or reduce boredom and lack of motivation in repetitive industrial processes $[11,12]$. The studies show that implementing gamification in a production environment is not an easy task because of other competing requirements such as cost and quality. Despite these requirements, production instructors are interested in gamification because it is an attractive approach that can motivate employees and avoid burnout [10]. In addition, it appears that by using gamification, the mean time per production sequence is significantly reduced [12].

Gamification can be beneficial, but it is not easy to implement as some companies tried to use it without success [10]. It is crucial to clearly identify the purpose and the content that the user might learn. Otherwise, gamification becomes a costly and ineffective tool as the users do not improve the expected skills; they can still have fun, but this is not the main goal of gamification.

\subsection{VR and gamification}

Combining VR and gamification is a good way to engage the player more than just using gamification alone as previously [13]. VR matches well with gamification tools and techniques because it creates a playful and realistic environment. The player is much more engaged in a VR environment rather than a computer screen for instance. This blend has not been used in many scientific papers for industry concerns, but it is still a combination that is becoming popular to train and educate employees to specific tasks, such as safety tasks [15] or to train new employees [16].

VR and gamification are currently mostly applied to address social concerns rather than industrial applications. For instance, a VR educative application has been developed to learn a new language [17], another one has been created to reduce the preoperative anxiety of children with a game designed to educate pediatric young patients before a general anesthesia [18].

Some prerequisites are essential for the user to feel present in a VR game, these are: a realistic environment and a high-quality information [19]. In turn, thus can increase player's performance and therefore knowledge gained. This presence feeling can be achieved by an immersive experience that raises the user's involvement. [20]. The benefits of these educative games are that the user can do some mistakes before succeeding and retry until assimilating the principle [21]. There are still some problems to avoid using VR and gamification, for instance, staying too long in a VR environment can make the player dizzy or disoriented [17]. 


\subsection{Eco-efficiency}

Eco-efficiency is one of the main tools that can be used to transition to a more sustainable society [22]. It is achieved by increasing material and energy efficiency and reducing ecological impacts [23]. Industries are becoming more aware of the need and challenge to produce in a sustainable way using the eco-efficiency concept [24] and some tools have been developed to support its implementation in factories [23, 24, 25].

Firstly, we make use of an existing toolbox to promote eco-efficiency improvements [24, 25]. Secondly, the use of the appropriate KPIs (Key Performance Indicators) is needed for factories to improve their efficiency and make use of valuable data [23, 24].

\subsection{Synthesis}

Several positive effects from previous studies showed that gamification and VR are two tools that can help industry and increase the acceptance of gamification. This combination is becoming more popular in industry and could also integrate ecoefficiency concerns. Our contribution would be to create a new powerful tool to help industry in training and educating people for more efficient operations using VR, gamification and eco-efficiency.

To do so, the idea is to take into consideration the outcomes of the previous studies in order to keep the benefits of VR and gamification and eliminate the deficits. It is important to have a game that can be finished in a reasonable period to avoid dizziness and vertigo. In addition, clearly identify the eco-efficiency improvements areas is primordial for the user to assimilate it and being aware if the environmental impact of his job. Thirdly, the game design is one of the focus to develop an effective tool that provides all the necessary content for the player to meet the learning objectives.

\section{Experiment}

This section presents the VR application developed for the shipping industry with the aim to educate the user to load trucks on a RoRo ship in an eco-efficient way. It means that the player can develop his technical skills and being aware of the environmental impact of the loading operation while being immersed in a $3 \mathrm{D}$ virtual environment. Section 2.1 describes the background of the project and the challenges encountered. Section 2.2 shows how the game was designed and Section 2.3 how it was developed. Finally, Section 2.4 shows the outcomes of the experiment.

\subsection{Background}

As digital and eco-efficient solutions are being developed to improve industrial operations, the ECOPRODIGI project [26] was launched in 2017 to help the shipping industry. In this context, VR, gamification and eco-efficiency were combined for the training of stowage operations. The two main activities connected to the project were: modelling loading operations in a realistic manner, and integration of eco-efficiency concerns in the scoring system of the application to evaluate how eco-efficient the loading operations are. 
Regarding the content of the educative application in this experiment, the goal was to figure out the existing loading techniques that are used during the stowage operations in order to implement them in the training game. To do so, the loading operations of a RoRo ship were studied directly at the port during the stowage process, which showed that the main concern of this operation is the stability of the boat. Firstly, an important indicator for the loading operation is the gravity point which must be as low as possible. Secondly, the loading officer must be careful about the angle of list, that is the degree of inclination of the boat according to port or starboard, which ideally should be zero. Thirdly, the trim angle is the difference between the back and the front of the boat, which is less important than the angle of list but still is of importance. These three concerns are the main content that the user should learn in the educative application to develop technical skills. In the meantime, the board table and plans of the loading officer has been observed in order to add it in the game.

In addition to the three main stability indicators (angle of list, angle of trim and the gravity point position), the loading speed was also connected to eco-efficiency. The game aims to educate users about the environmental impact of their decisions and provide knowledge on how to tackle these concerns in practice. For the loading time, 15 minutes saved equals to 1 ton of fuel saved. Indeed, if the loading is faster, the boat can sail slower with reduced fuel consumption. If the stability of the boat is not efficient, it must be compensated by water reserves stored in the hull of the boat. So better stability of the RoRo ship means that the water reserves can be reduced, and therefore, the boat is lighter, and the fuel consumption reduced. These are two examples of how the eco-efficiency concept can be used to reduce environmental impacts by using fewer natural resources while saving money.

\subsection{Game design}

\subsubsection{Game design theories}

Before developing a game, the design features must be carefully considered based on the purpose of the application. The first question is: "Which level of gamification do we want?". Three different levels of gamification can be distinguished (Figure 1): superficial gamification, deeper gamification, and game-based learning [27].
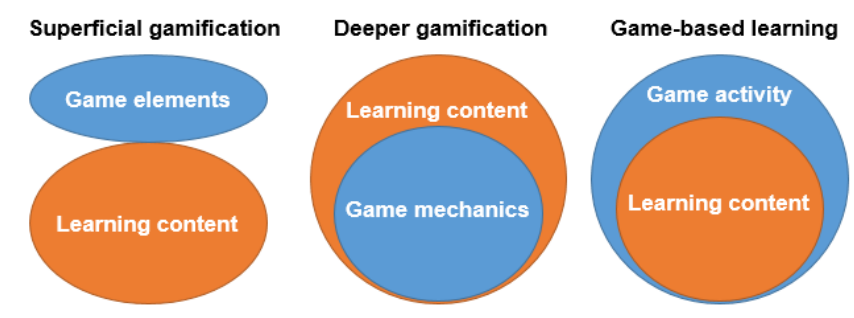

Figure 1. Different levels of gamification based on [26].

Superficial gamification engages the user by using the basic elements of video games with the creation of an avatar, the presence of a score and rewards system. Some companies use this level of gamification in their fidelity application to reward their customers. Deeper gamification involves the player by creation a competitive environment with games such as quizzes. Example of deeper gamification are the business games used in companies and universities to simulate supply chains and factory 
management scenarios for instance. Game-based learning means that the learning content is fully embedded in a game and the learning objectives are delivered through game elements and game mechanics. As a consequence, the user receives the educative content while being immersed in a playful environment, it involves the player way much more.

Game-based learning was chosen because it carries the user into a unique experience and engages the player in the game to bring a higher motivation.

\subsubsection{The Bloom's taxonomy}

According to the Bloom's taxonomy [28] there is five levels of affective learning which can be applied to gamified learning [27]: Receive, Respond, Value, Organize and Characterize. Table 1 explain how they will be defined for the educative game that aims to improve the stowage operation of the shipping industry.

Table 1. Bloom's taxonomy levels and associated game activities.

\begin{tabular}{|c|c|c|}
\hline Level & Objective & Game activity \\
\hline \multirow[t]{6}{*}{ Receive } & \multirow[t]{6}{*}{$\begin{array}{l}\text { Engage the player in the } \\
\text { game }\end{array}$} & $\begin{array}{l}\text { - Attractive design, playful and realistic thanks to VR } \\
\text { and the 3D scan (model) of a real RoRo ship }\end{array}$ \\
\hline & & $\begin{array}{l}\text { - Avatar creation to guide the user along the adventure } \\
\text { and create a friendly atmosphere }\end{array}$ \\
\hline & & - Easy-to-understand rules \\
\hline & & $\begin{array}{l}\text { - Tutorial videos and pictures to help the user understand } \\
\text { how the game works }\end{array}$ \\
\hline & & - Competitive environment with multi-player sessions \\
\hline & & - All the gaming elements present in the field of view \\
\hline \multirow[t]{2}{*}{ Response } & \multirow[t]{2}{*}{ Conform with rules } & - Handy game techniques that everyone can play \\
\hline & & $\begin{array}{l}\text { - Decision making game so the player should not be } \\
\text { disturbed with difficult game controls }\end{array}$ \\
\hline \multirow[t]{3}{*}{ Value } & \multirow{3}{*}{$\begin{array}{l}\text { Give meaning to the } \\
\text { rules }\end{array}$} & - Tracking of the most eco-efficient loading \\
\hline & & $\begin{array}{l}\text { - Scoring system using loading speed, stability or gravity } \\
\text { point position }\end{array}$ \\
\hline & & $\begin{array}{l}\text { - Eco-efficiency KPI called the "leaf" as points to rank } \\
\text { players on the leaderboard }\end{array}$ \\
\hline \multirow[t]{2}{*}{ Organize } & \multirow[t]{2}{*}{$\begin{array}{l}\text { Take actions according } \\
\text { to the game objectives }\end{array}$} & $\begin{array}{l}\text { - The player must find the best technique to load the } \\
\text { trucks as fast as he can. }\end{array}$ \\
\hline & & $\begin{array}{l}\text { - The user may question himself when failing a level in } \\
\text { order to go through and solve it. This is an instructive } \\
\text { task for the player to develop his skills but also his } \\
\text { decision making and adaptability }\end{array}$ \\
\hline \multirow[t]{3}{*}{ Characterize } & \multirow[t]{3}{*}{$\begin{array}{l}\text { Apply the game } \\
\text { learning knowledge in } \\
\text { reality }\end{array}$} & $\begin{array}{l}\text { - The user gains a new understanding of stowage } \\
\text { operations and how they affect eco-efficiency } \\
\text { performance }\end{array}$ \\
\hline & & $\begin{array}{l}\text { - The user practices concrete and realistic eco-efficient } \\
\text { operations }\end{array}$ \\
\hline & & $\begin{array}{l}\text { - The user develops good habits to make eco-efficient } \\
\text { practices more intuitive }\end{array}$ \\
\hline
\end{tabular}




\subsection{Game development}

\subsubsection{Hardware and software}

To fill in all the prerequisites mentioned before, the development platform "Unity" was chosen. A collection of scripts for VR applications from the VRTK (Virtual Reality Toolkit) was used within Unity. Some predefined tools, like a pointer or a teleport, can be found in VRTK. SteamVR was used to communicate with the VR headset. Finally, all the scripts were written in C\# using Visual Studio, a development software.

As for the hardware, a HTC Vive headset has been used. It has a refresh rate of $90 \mathrm{~Hz}$, a $110^{\circ}$ view angle with a screen of 2160 by 1200 pixels. This technology enabled us to create a more immersive environment and a more realistic experience of the loading operations.

\subsubsection{Game overview}

From a user perspective, the complexity of loading operations and eco-efficiency factors should be incrementally added to have a progressive adventure that goes from the easiest to the hardest level. The chosen format and description of individual levels is explained in Table 2.

Table 2. Learning content of each level.

\begin{tabular}{lll}
\hline Level & Learning outcome & Points \\
\hline 1 (turorial) & Loading technique, priorities & 0 \\
\hline 2 & Weight concept & 3 \\
\hline 3 & Angle of list + random trucks appearance & 3 \\
\hline 4 & Adding trucks to load & 5 \\
\hline 5 & Angle of trim & 5 \\
\hline 6 & Gravity point & 7 \\
\hline 7 & Different sizes & 5 \\
\hline 8 & Dangerous freight & 5 \\
\hline
\end{tabular}

Level 1 is similar to a tutorial in the sense that there is no score calculation to the player can learn the game mechanics without any pressure. The scene (game environment for each level) has been designed to engage and involve the player by exploring the game elements and mechanics. This tutorial also has the objective to highlight the loading priorities that apply in all levels of the game.

Level 2adds a weight variable to introduce the player to the first stability indicators. The score calculation begins from this level, tracking the most eco-efficient stowage based on the loading speed.

Level 3 adds the angle of list which is the second stability indicator used in reality by the loading officer. Stability indicators have been added visually in the scene to inform the user about the value of the angle of list in real time. From this level and until the end, the trucks will appear in a random order to improve the player's anticipatory and planning capacity. 
In Level 4, the player must load more trucks, 16 instead of 8 in the previous level. This is the maximum number of freights for a single level as to not tire the player. As the game is becoming more difficult, there is now 5 "leaves" (in-game points) to grab thanks to the stability (angle of list) and the speed of loading.

Level 5 brings the angle of trim variable which means that there are the two stability indicators in the game. More, a board table similar to the one used by the loading officer has been add in the scene, this makes the environment more realistic.

In Level 6, the player experiences a scene that is closer to reality because it makes use of all three stability indicators by adding the gravity point position. This level integrates critical learning content; thus, the player can gain 7 "leaves" in this scene.

Finally, two more levels were created to challenge the player further: Level 7 introduces trucks with different sizes, and Level 8 includes some safety concerns with the addition of dangerous freight. Figure 2 and Figure 3 are screenshots of scenes that illustrate two levels (5 and 6 respectively).

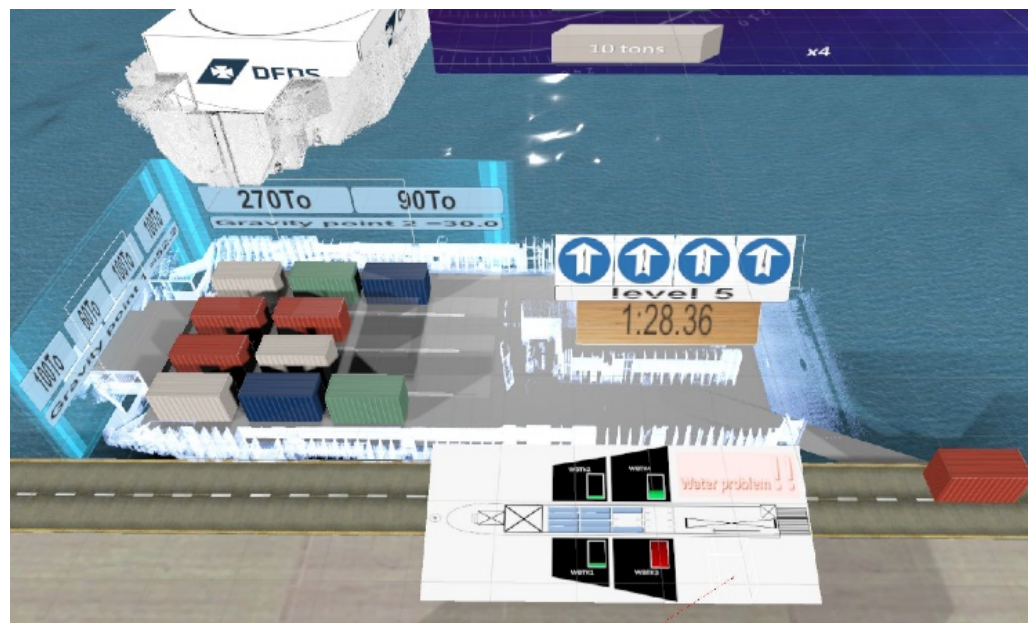

Figure 2. Overview of Level 5.

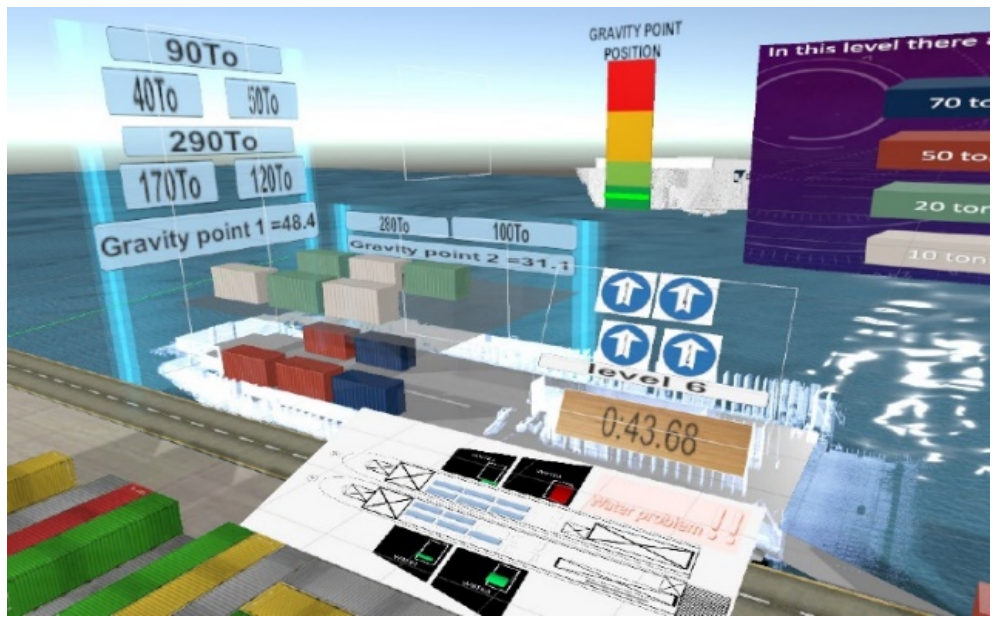

Figure 3. Overview of Level 6. 
To manage all these levels, a "Menu room" scene has been created (Figure 4). This is where the player appears when starting the game. This scene is composed of three areas: Options area, Player area, Adventure area.

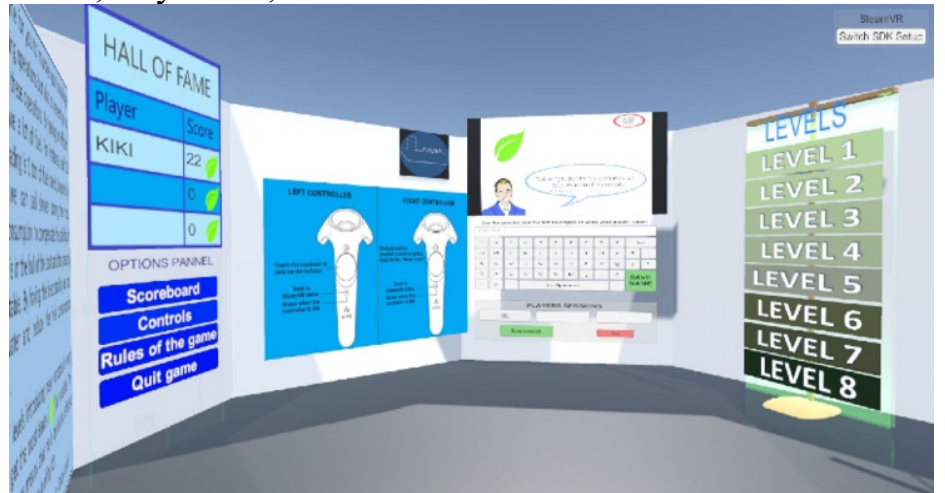

Figure 4. The "Menu room" from left to right: Options area, Player area and Adventure area.

This scene is maybe the most important of the game because this is where the player and score management takes place. Indeed, all the levels communicate with the "Menu room" to update the players' overall score. Then, with all the global scores of each player, a leaderboard has been added to create a playful competition between the players.

\subsection{Outcomes}

During the game development and once the game was completed, we tested the game to collect feedback using post-test questionnaire and semi-structured interview on impressions, feelings and ideas from a player perspective and improve both the gaming and learning experiences. We also tested the game with maritime industry professionals to check the accuracy of the game using their expert and practical knowledge of the subject. We had the opportunity to present and test the game at a seminar for the ECOPRODIGI project in Turku (Finland), which gathered industries and various stakeholders from the shipping industry. A port visits also allowed us to observe stowage operations in reality and gain a more in-depth knowledge of the processes.

The boat captain, the loading officer and some crew members tried the educative VR game. The game was well-received by the players. As the game is using VR, it engages the player with an immersive environment, which many people have never experienced before. The game controls were kept as simple as possible to increase accessibility and usability so everyone could play the game by just pointing and pressing the controller's trigger.

Finally, the player could feel the game progression and the link between levels with the addition of one performance variable in each scene. In addition, it brings a new vision of the loading operation thanks to the eco-efficiency KPI which is also used to rank players on the leaderboard. This ranking system was well-received because it creates a playful competition between the players. 


\section{Discussion and limitations}

\subsection{Discussion}

We strongly believe that this study could be expanded to train and educate people in any matter. The only prerequisites before starting this kind of project is to clearly define the purpose of the educative content. Then, this study gives all the clues to design such a professional training game, like detecting the main concerns that the user might learn, figure out the eco-efficiency improvements and designing a progressive adventure going from easy to hard by incrementally introducing new performance variables in each level.

Like in a previous study [17], we noticed that VR really engaged participants and they enjoyed the VR experience, it shows the impressive potential for training and educative concerns.

In the meantime, it is important to keep a realistic environment as the user lives the seamless experience in reality [5]. Of course, the player will not have a same point of view than in the game but he/she will not get lost when applying their knowledge, they learned through the game, in reality.

We are convinced that this blend composed of eco-efficiency, gamification and VR is a good way to promote and get a sustainable way of production and as a finality a sustainable society in order to reach the SDG within 2030 [1]. We think that new technologies must be at the service of the most important concerns that the world face and now, environmental concerns are unfortunately the biggest challenge that must be solve. VR and other digital technologies generate great attraction from industry and the general public. They represent a good opportunity to be used as a vehicle to generate more interest in sustainability issues. In this regard, the application presented in this study is especially adapted to address the 4th SDG on quality education, focusing on ecoefficiency in the shipping industry.

Moreover, training people using VR and gamification is a win/win solution for everyone in the factory. On the one hand, the employee can train himself when he wants to improve his skills because there are no special requirements, such as the need of an instructor or a special location for instance. On the other hand, the factory can save money for the education of their employees as a VR setting can easily be changes and avoid costly modification to real products or facilities.

The eco-efficiency is a good addition to encourage employees to explore and learn about this concept, but it is also important to involve them in the continuous improvement process of the factories, in line with the 12th SDG on responsible production [1].

\subsection{Limitations}

However, it is important to be aware while using these concepts to clearly identify the purpose of the subject, in particular the eco-efficiency concerns. Indeed, gamification can be ineffective if the game is not adapted to the topic. It can become a waste of time and money as it does not achieve the objectives of eco-efficiency.

A training game like the one we experimented also has some limitations. It creates a first understanding of the eco-efficiency in the loading operations; but if the user wants to load trucks in a ship as his job, he must obviously get some other theoretical and practical knowledge, such as safety, which the game does not cover [29][30].

Finally, the educative game should not be too long in order to not tire the user as this is a static game with game controls that never change [31]. That is why it has been 
decided to have only eight levels because it seemed to be the ideal number of scenes to give all the educative content needed while not boring the player. Another tip that has been applied to avoid weariness was to have a maximum of 16 trucks to load.

\section{Conclusion}

This project aimed to show how to train and educate people effectively for eco-efficient operations using VR and gamification. It shows all the prerequisites needed to build a VR application and the main points to focus on how to design an educative tool using gamification, and how to bring sustainability into practice using to eco-efficiency.

This experiment received positive feedback from users in industry. The application presented in this paper can be useful to train operators or educate students in eco-efficient ship loading operations. The study demonstrates how new technologies, such as VR, have a big potential to support industries and help them to operate more sustainably. The experiment also showed that VR, gamification and eco-efficiency can contribute towards the 4th SDG on quality education. As a result, by training employees taking account of the eco-efficiency concerns, it is a good way to develop employees' skills to systematically consider eco-efficiency and involve them in continuous improvement to improve their job and tasks to operate in a more sustainable way and contribute to the 12th and 13th SDGs on responsible production and climate action.

This study opens a discussion about the benefits and the limitations of this kind of educative application. We suggest further work in combining VR, gamification and ecoefficiency for other operations or other industries in order to increase awareness and knowledge for more sustainable operations and a more sustainable society.

\section{Acknowledgements}

This work was supported by Ecoprodigi funded by the EU agency Interreg Baltic Sea Region under Grant number R070 and carried out in the Production Area of Advance at Chalmers University of Technology. The support is gratefully acknowledged.

\section{References}

[1] United Nations, Transforming our world: the 2030 Agenda for Sustainable Development, Accessed: September 2015 [Online]. https://sustainabledevelopment.un.org/post2015/transformingourworld

[2] Mohd.Fairuw Shiratuddin, Virtual Reality in Manufacturing, January 2001.

[3] Muhammad Azhar Hussain, Virtual Reality Projection Based Furniture Showroom-A Hypthetical Study of BPR Implementation in a Small Business of Furniture Design \& Supplier, December 2017, Bahria University Journal of Information \& Communication Technologies Vol. 10, Issue II.

[4] Gilles Wagner, Continuous Improvement Process in Virtual Reality, April 2007.

[5] Liang Gong, Development of virtual reality support to factory layout planning, 2018.

[6] Sebastian Deterding, Gamification: Using Game Design Elements in Non-Gaming Contexts, May 2011, CHI 2011, Vancouver, BC, Canada.

[7] Michael Sailer, How gamification motivates: An experimental study of the effects of specific game design elements on psychological need satisfaction, August 2016, ELSEVIER, Computers in Human Behavior Volume 69, pages 371-380, DOI: https://doi.org/10.1016/j.chb.2016.12.033 
[8] Benjamin Sawe, The concept Of Eco-Efficiency: Why Is It So Important For The Modern World, April 2017,https:/www.worldatlas.com/articles/the-concept-of-eco-efficienty-why-is-it-so-important-for-themodern-world.html

[9] McGonigal, J. 2011. Reality is broken: Why games make us better and how they can change the world. Penguin books.

[10] Karen Robson., Plangger, K., Kietzmann, J.H., McCarthy, I., Pitt, L., Game on: Engaging customers and employees through gamification, 2015, Bus. Horiz. 59, 29-36.

[11] Oliver Korn, Gamification of Production? A Study on the Acceptance of Gamified Work Processes in the Automotive Industry, July 2016, Springer, W.Chung and C.S. Shin, Advances in Affective and Pleasurable Design, pages 433-445, DOI : 10.1007/978-3-319-41661-8 42

[12] Oliver Korn, Towards a Gamification of Industrial Production. A Comparative Study in Sheltered Work Environments, June 2015, ACM, EICS '15, Duisburg, Germany, DOI: http://dx.doi.org/10.1145/2774225.2774834.

[13] Parthasarathy Vinukonda, Virtual Reality and Gamification: A Blend for Better Learning Outcomes and Performance, November 2018, https://trainingindustry.com/blog/learning-technologies/virtual-realityand-gamification-a-blend-for-better-learning-outcomes-and-performance/

[14] Bekelis, K., Calnan, D., Simmons, N., Effect of an Immersive Preoperative Virtual Reality Experience on Patient Reported Outcomes: A Randomized Controlled Trial, June 2017, Annals of Surgery, Volume 265, Number 6.

[15] Dennis Daniel, Working At Height Training With VR And Gamification, May 2018.https://www.pmvmiddleeast.com/70957-working-at-height-training-with-vr-and-gamification

[16] ImmersiveVR, Game On: Increase Employee Efficiencies and Training Retention with Virtual Reality, Accessed: January,2019. Available:https:/immersivevrtechnologies.com/2019/01/02/game-on-increaseemployee-efficiencies-and-training-retention-with-virtual-reality/

[17] Alan Cheng, Teaching Language and Culture with a Virtual Reality Game, May 2017, CHI'17, Denver, $\mathrm{CO}$, USA.

[18] Jung-Hee Ryu, The Effect of Gamification through a Virtual Reality on Preoperative Anxiety in Pediatric Patients Undergoing General Anesthesia: A Prospective, Randomized, and Controlled Trial, August 2018, Journal of Clinical Medicine, 7(9), 284.

[19] Martin Usoh, Using Presence Questionnaire in Reality, Presence: Teleoperators and Virtual Environment 9, 5 (2000) 497-503.

[20] Bob G Witmer and Michael J Singer. 1998. Measuring presence in virtual environments: A presence questionnaire. Presence: Teleoperators and virtual environments 7, 3 (1998), 225-240.

[21] Randy S Haluck and Thomas M Krummel. 2000. Computers and virtual reality for surgical education in the 21 st century. Archives of surgery 135, 7 (2000), 786-792

[22] Bing Zhang, Eco-efficiency analysis of industrial system in China: A data enveloment analysis approach, December 2008, Ecological Economics 68 (1-2):306-316.

[23] May, G., Barletta, I., Stahl, B., Taisch, M., Energy Management in Production: A novel Method to Develop Key Performance Indicators for Improving Energy Efficiency, July 2015, Applied Energy 149:46-61.

[24] Despeisse, M., Davé, A., Litos, L., Roberts, S., Ball, P., Evans, S. A Collection of Tools for Factory Ecoefficiency. Procedia CIRP 40 (2016), 542-546.

[25] Despeisse, M., Lunt, P. Teaching energy efficiency in manufacturing using gamification: A case study. IFIP Advances in Information and Communication Technology 514 (2017), 419-426.

[26] ECOPRODIGI, Bringing eco-efficiency and digitalization to maritime industry, October 2017, http://ecoprodigi.eu/project-2

[27] Despeisse, M., GAMES AND SIMULATIONS IN INDUSTRIAL ENGINEERING EDUCATION: A REVIEW OF THE COGNITIVE AND AFFECTIVE LEARNING OUTCOMES, December 2018, Winter Conference Simulation 2018, Gothenburg, Sweden.

[28] Krathwohl, D. R., Bloom, B. S., \& Masia, Taxonomy of Educational Objectives: The classification of educational goals. Handbook II: Affective Domain, 1964, University of Michigan, New York.

[29] A. C. A. Mól, C. A. F. Jorge and P. M. Couto, Using a Game Engine for VR Simulations in Evacuation Planning in IEEE Computer Graphics and Applications, vol. 28, no. 3, pp. 6-12, May-June 2008.

[30] Lin, Chiuhsiang Joe, et al. A Skill-, Rule-, and Knowledge-Based Interaction Design Framework for WebBased Virtual Reality Training Systems in Key Engineering Materials, vol. 450, Trans Tech Publications, Ltd., Nov. 2010, pp. 564-567. Crossref, doi:10.4028/www.scientific.net/kem.450.564.

[31] X. Liang, H. Kato, S. Higuchi and K. Okawa, High efficiency skill training of lathe boring operations by a virtual reality environment in 2012 IEEE International Conference on Mechatronics and Automation, Chengdu, 2012, pp. 285-290. 